\title{
A música como vontade e representação*
}

\author{
GüNTER ZÖller \\ Ludwig-Maximilians-Universität München
}

ResUMO: $\mathrm{O}$ artigo apresenta uma reflexão sobre o lugar sistemático da música na filosofia de Arthur Schopenhauer. $\mathrm{O}$ foco das considerações não está nas doutrinas e detalhes particulares da filosofia da música de Schopenhauer, mas na fundamentação sistemática da música na doutrina transcendental do mundo que ele propõe. No centro da investigação está a integração estrutural e substancial da arte em geral, e da música em particular, à filosofia primeira em Schopenhauer. O artigo situa a elevação metafísica da música por Schopenhauer no contexto de sua dupla consideração do mundo como vontade e como representação, e examina sua apropriação produtiva de Platão e Kant. O foco está no projeto filosófico de Schopenhauer de articular a constituição dupla, mas unitária, do mundo. As seis partes do artigo, por sua vez, dedicam-se ao intento unificador da filosofia de Schopenhauer com relação a metafísica e ética, metafísica e estética, ética e estética, arte e filosofia, música e mundo, vontade e representação.

Palavras-chaves: filosofia da música; estética; vontade; Schopenhauer; Kant; Platão; Hanslick
ABSTRACT: The article presents a sustained reflection on the systematic place of music in the philosophy of Arthur Schopenhauer. Rather than targeting the particular doctrines and details of Schopenhauer's philosophy of music, the article focuses on the systematic grounding of music in Schopenhauer's transcendental theory of the world. At the center of the investigation stands the structural and substantial integration of art in general and of music in particular into first philosophy in Schopenhauer. The article places Schopenhauer's metaphysical elevation of music into the context of his twofold consideration of the world as will and as representation and examines his productive appropriation of Plato and Kant. Throughout the focus is on Schopenhauer's philosophical project of articulating the twofold but unitary constitution of the world. The six sections of the article address, in turn, the unificatory intent of Schopenhauer's philosophy with regard to metaphysics and ethics, to metaphysics and aesthetics, to ethics and aesthetics, to art and philosophy, to music and world and to will and representation.

Kerwords: philosophy of Music; aesthetics; will; Schopenhauer; Kant; Plato; Hanslick

* Agradeço ao Prof. Marco Aurélio Werle pelas valiosas sugestões feitas durante o processo de tradução do presente artigo. 
A essência da música como essência do mundo ${ }^{1}$

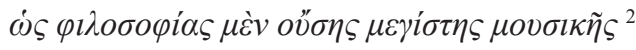

$\mathrm{O}$ artigo apresenta uma reflexão sistemática acerca do lugar arquitetônico da música na filosofia de Schopenhauer. O foco das considerações não está nas doutrinas e detalhes da estética musical de Schopenhauer ${ }^{3}$, mas em sua fundamentação metódica de uma filosofia da música. ${ }^{4}$ A renúncia à exposição de aspectos específicos da estética musical de Schopenhauer está apoiada na conviç̧ão de que as forças e potenciais do pensamento estético de Schopenhauer não se encontram em suas avaliações estético-normativas da música ou mesmo em suas preferências musicais pessoais, mas em uma apreensão original das condições estruturais e substanciais da essência e do efeito da música, em virtude das quais a "maravilhosa arte dos sons" está predestinada a ser a arte metafísica propriamente dita.

1. Nietzsche, F. Nachlaß 1869-1874. In: . Kritische Studienausgabe. Vol. 7. Hrsg. von Giorgio Colli und Mazzino Montinari. Berlin, New York: Walter de Gruyter, 1999, p. 73.

2. Platão, Fédon 61a: "weil nämlich die Philosophie die vortrefflichste Musik ist" ["pois a filosofia é a mais excelente música”]. Tradução alemã de F. D. E. Schleiermacher.

3. Sobre as características e detalhes essenciais da estética musical de Schopenhauer cf. Zöller, G. "Arthur Schopenhauer“. In: Fürbeth, O.; Sorgner, S. (Hrsg.) Musik in der deutschen Philosophie. Eine Einführung. Stuttgart, Weimar: Metzler, 2003, p. 99-114.

4. A ambiciosa denominação "filosofia da música" - em oposição aos títulos das disciplinas "estética da música" ou "estética musical" - encontra-se no prefá cio do ensaio sobre Beethoven escrito por Richard Wagner no ano de 1870, o qual, em continuação à metafísica da música schopenhaueriana, expõe a espiritualidade específica da música de Beethoven recorrendo à categoria estética do sublime. Cf. Wagner, R. "Beethoven". In: Dichtungen und Schriften. Jubiläumsausgabe in zehn Bänden. Hrsg. von Dieter Borchmeyer. Bd. 9. Frankfurt/M: Insel, 1983, p. 38. Também Adorno utilizou o subtítulo "Filosofia da Música" para seu projeto de livro sobre Beethoven, que ele não chegou a concluir. Cf. Adorno, T. W. Beethoven. Philosophie der Musik. Fragmente und Texte. Hrsg. von RolfTiedemann. Frankfurt/M.: Suhrkamp Verlag, 1993, p. 10 e ss.

5. Schopenhauer, A. Die Welt als Wille und Vorstellung. Erster Band. In: Sämtliche Werke. Hrsg. von Arthur Hübscher. Dritte Auflage. Wiesbaden: Brockhaus, 1972, p. 303. 
No centro da reconstrução sistemática está o pertencimento estrutural e substancial da arte - e com ela, da música - ao âmbito de objetos da filosofia. A fundamentação de Schopenhauer da posição estética privilegiada da música é então situada no contexto sistemático de sua dupla consideração metafísica do mundo como vontade e como representação, e no contexto histórico de sua discussão crítico-produtiva com Platão e Kant. Em nossa abordagem iremos ressaltar principalmente o esforço de Schopenhauer de articular a composição unitária do mundo estruturado em sua complexidade. O interesse específico está voltado para as diferentes - porém correspondentes - configurações dos resultados sistemáticos unificadores na filosofia de Schopenhauer, que abarcam a relação da metafísica e da ética, da metafísica e da estética, da ética e da estética, da arte e da filosofia, da música e do mundo, bem como da vontade e da representação. A sucessão destes seis temas duplos determina a estrutura do artigo no mesmo número de seções.

\section{I. "A unicidade de metafísica e ética" 6}

O sistema filosófico de Schopenhauer, dividido em quatro partes, disponível na versão impressa de 1818, na versão das conferências proferidas em Berlim, de 1820, e na versão impressa essencialmente revisada e ampliada, de 1844, representa uma continuação e uma execução pós-clássicas originais do duplo programa crítico-idealista de uma doutrina dos princípios transcendentais do saber e de uma teoria metafísica do absoluto e de sua aparição. Com Kant, Reinhold e Fichte - ou, de maneira mais exata: com o Kant das três Críticas, o Reinhold da filosofia elementar e o Fichte de Jena - Schopenhauer partilha a orientação crítico-gnosiológica da filosofia em relação às condições, possibilidades e limites do saber do si-mesmo [Selbst] e do mundo. Ele se une a Fichte, Schelling e Hegel - ou, mais precisamente, ao Fichte tardio, ao Schelling intermediário e ao Hegel maduro - quanto à

6. Schopenhauer, A. Der handschriftliche Nachlaß. Hrsg. von Arthur Hübscher. Vol.1. Frühe Manuskripte (1804-1818). München: Deutscher Taschenbuch Verlag, 1985, p. 55. 
ampliação metacrítica para além do saber possível e seus objetos na direção do fundamento originário, do não-fundamento ou do abismo do saber em um incondicionado concebido de maneira subjetivo-teorética ("vida”, "ser", "Deus" ou "Espírito"). ${ }^{7}$

Contudo, Schopenhauer distingue-se tanto das intervenções e realizações de teoria do conhecimento e críticas da metafísica, quanto das intervenções e realizações pós-críticas metafísicas dos predecessores e contemporâneos - e isto sob um duplo ponto de vista: metodicamente, por meio de uma perspectiva ${ }^{8}$ empirista-falibilista - provavelmente marcada pelo ceticismo humeano de seu professor em Göttingen, Gottlob Ernst Schulze (“Aenesidemus”) - que reduz a especulação metafísica à explicação hipotética de fatos de todo tipo - e objetivamente, por meio da concepção anti-idealista de uma racionalidade que vai além [Präterrationalität] do absoluto ("vontade") - que provavelmente foi aprofundada pelo Fichte tardio e talvez também pelo Schelling intermediário, a partir da facticidade da aparição do absoluto pensada por ambos.

Tanto a continuidade quanto a descontinuidade em relação à filosofia clássica alemã caracterizam também a compreensão fundamental de Schopenhauer acerca da finalidade e do objetivo

7. Sobre o pertencimento de Schopenhauer à filosofia kantiana e pós-kantiana, Cf.: Zöller, G. "German Realism. The Self-Limitation of Idealist Thinking in Fichte, Schelling and Schopenhauer". In: The Cambridge Comnpanion to German Idealism. Hrsg. von Karl Ameriks. Cambridge: Cambridge University Press, 2000, p. 200-18; "Die Möglichkeiten und Grenzen der Vernunft. Kant und der deutsche Idealismus". In: Fischer, E.; Vossenkuhl. W. (Hrsg.) Die Fragen der Philosophie. Einfübrung in die Disziplinen und Epochen der Philosophie. München: C.H. Beck, 2003, p. 295312; cf. tambem . "Kichtenhauer. Der Ursprung von Schopenhauers Welt als Wille und Vorstellung in Fichtes Wissenschaftslehre 1812 und System der Sittenlehre”. In: Hühn, L. (Hrsg.) Die Ethik Arthur Schopenhauers im Ausgang von Deutschen Idealismus (Fichte/Schelling). In redaktioneller Zusammenarbeit mit Philipp Schwab. Würzburg: Ergon Verlag, 2006, p. 365-86.

8. Sobre a documentação da influência filosófica de Göttingen sobre Schopenhauer, cf. D’Alfonso, M. V. Schopenhauers Kollegnachschriften der Metaphysik- und Psychologievorlesungen von G. E. Schulze (Göttingen, 181011). Würzburg: Königshausen \& Neumann, 2008. 
da filosofia em geral, e especificamente de sua fundamentação e realização como metafísica crítica e pós-crítica da experiência. Já cedo, ainda na fase de planejamento e de sua primeira elaboração, Schopenhauer concebe seu sistema filosófico como "unicidade de metafísica e ética" ${ }^{9}$ Com a integração radical de metafísica e ética em uma apreensão, concebida unificadamente, da realidade determinada pela vontade enquanto profundamente marcada pelo prazer e pelo sofrimento, e necessitando inevitavelmente do consolo e da redenção, Schopenhauer retoma - numa forma modificada - o acordo metafilosófico de teoria e práxis, de filosofia prática e teórica, assim como do conhecimento e do agir, que caracterizou especialmente e de modo penetrante o pensamento de Kant e de Fichte, marcando até o íntimo de sua fatura suas construções teóricas e especulativas.

O si-mesmo liberto da vontade e o apaziguamento final na desmotivação e na inatividade colocam-se em Schopenhauer, sem dúvida, no lugar da liberdade possibilitada teoreticamente, da liberdade "salva", no agir individual e social determinado racionalmente, e colocam-se também no lugar da filosofia do homem livre, determinado a uma determinação de si-mesmo [zur Selbstbestimmung bestimmt]. Mas, Schopenhauer substitui sobretudo a concepção normativa da razão puramente prática e da determinação da vontade puramente racional em Kant e Fichte pelo auto-enfraquecimento da vontade, fundamentando-a cognitivamente numa figura articulada de maneira dupla: como um conhecimento do sofrimento produzido teoricamente e como conhecimento prático efetivo por meio do sofrimento.

Porém, na autodescrição do sistema da filosofia de Schopenhauer como "unicidade de metafísica e ética" reside não apenas a herança da integração arquitetônica entre filosofia transcendental e filosofia moral em Kant e sua fusão na Doutrina da Ciência de Fichte. Pelo contrário, a formulação da unidade entre metafísica e ética por Schopenhauer indica a concepção originária

9. Schopenhauer, A. Der handschriftliche Nachlaß, vol. 1, Frühe Manuskripte (1804-1818), p. 55. 
e final da metafísica como ética, assim como, inversamente, da avaliação da ética como metafísica. A metafísica realizada desemboca na ética tornada metafísica. A metafísica da vontade se transforma numa ética metafísica do não-querer. A forma de transcurso do sistema da filosofia em Schopenhauer, que vai da liberdade absoluta da vontade - e, com isto, da não-liberdade dada do intelecto - para a (auto-)aniquilação da vontade por meio do intelecto libertado replica assim a estrutura da outra grande obra que pensa unificadamente a metafísica e a ética, a Ethica de Espinosa, com a qual o sistema de Schopenhauer também partilha a concepção cognitivista da ética, a recondução do sofrimento às paixões e a convergência sistemática para a função libertadora do conhecimento filosófico.

\section{A unicidade de metafísica e estética}

No arcabouço sistemático da filosofia de Schopenhauer, à passagem da metafísica do querer para o não-querer corresponde a dissociação do sujeito do conhecimento diante do sujeito do querer, por meio da qual a autonomia originária do intelecto frente à vontade, ao destituir a funcionalidade desta, é restituída através e para a vontade. No sistema de Schopenhauer, a passagem da liberdade da vontade para a liberdade do intelecto e, com isto, da metafísica da vontade para a ética do não-querer, é assegurada pela arte em seu significado metafísico ("Metafísica do Belo"10). Schopenhauer situa a Filosofia da Arte na posição estrategicamente central entre a auto-afirmação da vontade que se torna mundo ("mundo como vontade") e a autonegação da vontade que ultrapassa a nulidade do mundo. Com a orientação mundana da vontade a esfera da arte partilha a orientação para a objetidade da Vontade ["Objektitäat"11] e os modos de suas objetivações [“Objektivationen"12], com o afastamen-

10. Este é o título da terceira parte do ciclo de preleções de Schopenhauer sobre o Sistema da Filosofia. Cf. Schopenhauer, A. Metaphysik des Schönen. Hrsg. von Volker Spierling. München, Zürich: Piper, 1985, p. 37.

11. Schopenhauer, A. Die Welt als Wille und Vorstellung. Erster Band. In: Sämtliche Werke, p. 152.

12. O subtítulo do segundo livro do Mundo como Vontade e Representação é: "A objetivação da Vontade" (Schopenhauer, A. Die Welt als Wille und Vorstellung. Erster Band.In: . Sämtliche Werke, p. 111). 
to da ética diante do mundo ela está ligada pelo fato de ter como meta a suspensão da vontade na forma da contemplação estética. Para Schopenhauer a arte é capaz - pálida e momentaneamente de conseguir o que a atitude ética praticada de maneira radical pode proporcionar de maneira completa e duradoura através do rompimento ascético da vontade.

A posição intermediária da estética, introduzida e executada como metafísica da arte, é fundamentada por Schopenhauer com o caráter específico de conhecimento da arte, tanto em sua produção como em sua recepção. Diferentemente do conhecimento habitual dos objetos no espaço e no tempo - fundamentado segundo a sua possibilidade no Livro I de sua obra principal - e que resulta do princípio transcendental da individualidade na forma do princípio de razão suficiente, os objetos da produção e recepção estética não podem ser classificados nem espacialmente nem temporalmente, nem estão submetidos às regras de associação quadruplamente diferenciadas, da racionalidade ôntica, eficiente, epistêmica ou motivacional. A liberdade do [âmbito] estético com relação à racionalidade e à individualidade lembra, assim, a independência e autonomia além-racional [präterrationale] da Vontade, aquém de sua manifestação constitutivamente regrada como mundo no espaço e no tempo.

Mas Schopenhauer também acentua a radical diversidade entre o conhecimento estético desprovido de fundamento [grundlos] e o querer cósmico desprovido de fundamento. Diferentemente da vontade cega em si, o não-querer estético - enquanto forma ou figura do conhecimento - é dotado de visão ou de um olho. O conhecimento estético tem por objeto o que está fora do tempo, do espaço e da racionalidade suficiente, sem por isso coincidir com a vontade. Segundo a interpretação de Schopenhauer, estas são as Ideias enquanto objetivações imediatamente-primeiras da vontade. $\mathrm{Na}$ ontologia de Schopenhauer, estruturada de maneira crítica, as Ideias estão entre a própria vontade como tal e as coisas individuais no espaço e no tempo. ${ }^{13}$

13. Cf. Idem, p. 200 e ss. 
As Ideias têm em comum com a vontade a além-temporalidade e a além-espacialidade (praeter e não extra), assim como a absoluta ausência de fundamento [Grundlosigkeit] de sua subsistência e de sua relação recíproca. As Ideias não possuem nenhum fundamento [Grund] a partir do qual seguem uma legalidade e tampouco estão numa relação de causa e consequência entre si. Com as coisas individuais no espaço e no tempo, que estão sob o princípio geral da razão suficiente, as Ideias têm em comum o estatuto de objetos do conhecimento e, com isto, a correlação com um sujeito do conhecimento. Porém, o correlato subjetivo das Ideias não é um sujeito individual, tal como no caso dos objetos individuados racional e espaço-temporalmente, mas sim - em concordância com o caráter pré-individual e além-racional das Ideias - o sujeito genérico e pré-individual do conhecimento, independente de espaço, tempo e fundamentos de todo tipo.

Mediante as Ideias, como objetos do conhecimento exclusivos da arte, tanto na produção como na recepção, Schopenhauer ampliou o princípio kantiano de sua filosofia transcendental neo-metafísica com um elemento platônico. De acordo com a questão mesma, trata-se, junto às Ideias, de conceitos gerais ou dos universais, mais precisamente, trata-se de conceitos gerais apreendidos realisticamente, que devem ter consistência independentemente das coisas individuais instanciadas (universalia ante rem). Assim como em Platão e nos escolásticos realistas, as Ideias em Schopenhauer não são conceitos discursivos, mas objetos de tipo superior, conservados de maneira imediata, puras visões de uma realidade superior e não-sensível ( $\varepsilon \tilde{i} \delta \eta$, species). E assim como no platonismo ontológico, as Ideias desempenham em Schopenhauer o papel de quintessência dos princípios da determinidade objetiva das coisas individuais, as quais somente através das Ideias - nas quais participam, na medida em que estas as instanciam - são o que são: coisas individuais com propriedades universais.

Porém, as Ideias de Schopenhauer distinguem-se também de maneira essencial das Ideias de Platão e dos Universais dos realistas 
conceituais. Diferentemente das Ideias que perduram de maneira

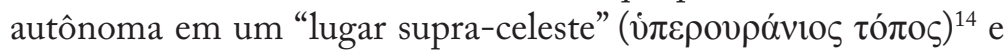
são universais reais, em Schopenhauer as Ideias estão ligadas ao sujeito de maneira constitutiva, e perduram somente em correlação com ele. $\mathrm{O}$ sujeito correlacionado às Ideias é então, ao invés do sujeito individual do conhecimento empírico, o sujeito "puro" supra-individual do conhecimento, no qual tratar-se-ia menos de um super-eu [Über-Ich] do que da quintessência dos princípios da objetividade de todo tipo, fundada no sujeito, tal como também as próprias Ideias em Schopenhauer seriam de se apreender como a quintessência de possíveis determinações objetivas.

Antes de Schopenhauer, Kant já havia submetido as Ideias de Platão a uma interpretação subjetiva-teorética e - com a designação de "conceitos especulativos da razão" - as transformou em conceitos discursivos de objetos não-sensíveis, os quais não são, enquanto tais, fundamentalmente instanciados, mas podem apenas ser aproximados de maneira infinita. ${ }^{15}$ Entretanto, em Kant as Ideias são correlatas não apenas com a subjetividade (transcendental). Pelo contrário, as Ideias kantianas são essencialmente produções ("produtos") da razão pura (especulativa), a qual se objetiva ${ }^{16}$ nelas como quase-objetos ("como se"), de acordo com o modo de operar das funções do juízo aplicadas à forma silogística. Não obstante, o fato de Schopenhauer retomar o processo genético subjetivo das Ideias presente em Kant deveria ser atribuído não tanto a uma maior proximidade com o conceito metafísico das Ideias de Platão, do qual ele se distingue especialmente por sua concepção das Ideias como além-racionais e, com isso, como extra-lógicas. Pelo contrário, manifesta-se nisso o ceticismo geral de Schopenhauer contra deduções específicas de tipo genético e contra o pensamento de desenvolvimento como um todo, na disposição e na execução da filosofia transcendental.

14. Platão, Fedro, 247c.

15. Cf. Kant, I. Crítica da Razão Pura, A 312 e ss./B 368 e ss.

16. Cf.Idem, A 642 e ss./B 670 e ss. 


\section{A unicidade de estética e ética}

Schopenhauer executa a dupla teoria transcendental do mundo como vontade e como representação segundo o modelo do "método analítico" de Kant nos Prolegômenos - como recurso hipotético do fato da experiência às condições de possibilidade de uma tal experiência. ${ }^{17}$ Diferentemente de Kant (e também de Fichte), Schopenhauer complementa a unilateralidade metódica da análise transcendental regressiva, mas não ao custo do procedimento sintético da gênese a priori ou da reconstrução genética ao modo de uma "história pragmática do espírito humano". ${ }^{18}$ Com isso, em Schopenhauer, suprime-se todo o "lado subjetivo" do programa de dedução kantiano ${ }^{19}$, assim como ele também não acolhe o recurso análogo de Fichte, que faz retroceder os fatos [Tatsache] da consciência aos "estados-de-ação" [Tathandlungen] que os fundamentam e os tornam possíveis. ${ }^{20}$ Porém, diferentemente de Kant e de Fichte, que fixam a tarefa [Einsatz] da filosofia transcendental primariamente no fato da experiência científica, a experiência que inicia e dirige o pensamento transcendental abarca também e principalmente o desprazer e o sofrimento como partes constitutivas da experiência do si-mesmo [Selbst $]$ e do mundo. ${ }^{21}$

17. Kant,I. Kant's Gesammelte Schriften.Hrsg. von der Preußischen Akademie der Wissenschaften (Bd. 1-22), der Deutschen Akademie der Wissenschaften zu Berlin (Bd. 23) und der Akademie der Wissenschaften zu Göttingen (a partir de Bd. 24). Bd. 4. Berlin, später Berlin, New York: Walter de Gruyter, $1900 \mathrm{e} s s$, pp. 263 e ss.

18. Fichte, J. G. J. G. Fichte-Gesamtausgabe der Bayerischen Akademie der Wissenschaften. Hrsg. von Reinhard Lauth u.a.. Bd. I. Stuttgart-Bad Cannstatt: Frommann-Holzboog, 1962ss, p. 72:365.

19. A esse respeito, cf. Kant, I. Crítica da Razão Pura, B 159; bem como a nota em: Kant, I. Kant's Gesammelte Schriften, bd. 4, p. 474. (Princípios Metafísicos da Ciência da Natureza).

20. A este respeito, cf. Fichte, J. G. J. G. Fichte-Gesamtausgabe der Bayerischen Akademie der Wissenschaften, bd. I/2, p.255 ("estado-de-ação"), assim como em Fichte, J. G. Züricher Vorlesungen über den Begriff der Wissenschaftslehre. Februar 1794. Nachschrift Lavater. Hrsg. Erich Fuchs. Neuried: Ars uma, 1996, p. 79 ("estados-de-ação").

21. Sobre o caráter fundamental patológico-soteriológico da filosofia sistemática de Schopenhauer, cf. Malter, R. Arthur Schopenhauer. 
Ao lado do exame das condições da possível experiência do sofrimento, na filosofia transcendental transformada de Schopenhauer em termos da noção de afeto, surge a questão da libertação possível da experiência do sofrimento e, com isso, a possibilidade da liberdade do sofrimento. A contribuição específica $\mathrm{da}$ arte para a dupla teoria transcendental schopenhaueriana da experiência do sofrimento e da libertação do sofrimento, reside na emancipação cognitiva da individualidade como condição fundamental do sofrimento. $\mathrm{O}$ conhecimento de tipo superior que penetra na produção e recepção artística das Ideias além-individuais afasta, através da orientação para objetos ideais, além e supraindividuais, o sujeito cognoscente do aprisionamento no espaço e no tempo e do princípio do sofrimento da individuação. $\mathrm{O}$ sujeito esteticamente deslocado torna-se, para além da correlação com os objetos além-individuais (Ideias), ele próprio um sujeito puro e além-individual. Isso o separa numa dupla distância do sofrimento: objetivamente, pela distância das coisas individuais provocadoras de sofrimento - que infligem entre si sofrimento e, subjetivamente, pela distância com relação àquilo que é responsável por todo o sofrimento: a vontade cega de viver.

Com seu duplo foco sobre o objeto puro das Ideias e o sujeito puro do conhecimento das Ideias, a estética schopenhaueriana da desindividuação de sujeito e objeto prefigura a libertação ética que repousa no conhecimento do caráter ilusório da individualidade e que consiste na negação ascética da Vontade. Para Schopenhauer, tanto na arte como na vida ética, a liberdade está na auto-libertação do domínio do princípio de razão suficiente enquanto principium individuationis. Porém, a forma estética e a forma ética de uma crítica da vontade vivida, eficaz em termos de vida, distinguem-se por meio de seu pertencimento a visões de mundo distintas. A visão de mundo estética da arte permanece

Transzendentalphilosophie und Metaphysik des Willens. Stuttgart-Bad Cannstatt: Frommann Holzboog, 1991. A esse respeito, ver também: Zöller, G. "Schopenhauer und das Problem der Metaphysik. Kritische Überlegungen zu Rudolf Malters Deutung”. In: Schopenhauer-Jahrbuch 77 (1996), p. 51-63. 
com sua orientação constitutiva para as Ideias no horizonte do mundo como representação, mesmo se o mundo aí vem à representação independentemente do princípio de razão suficiente. Ao contrário, a visão ética do mundo começa com o mundo como vontade, para então conduzi-lo ao autoconhecimento e à autonegação que disso resulta. Correspondendo às distintas orientações de mundo, encontra-se no centro da visão estética de mundo o conhecimento liberto da vontade e o prazer da contemplação, e no centro da consideração ética do mundo encontra-se a vontade de viver, junto à sua negação.

\section{A unicidade de filosofia e arte}

A classificação sistemática da arte ao mundo como representação, na medida em que a arte é considerada independente do princípio de razão suficiente, condiciona o caráter cognitivo específico da atitude estética com relação ao si-mesmo e o mundo em Schopenhauer. Afastando-se da tradição racionalista (Baumgarten), Kant tinha liberado a contemplação estética da pretensão a um conhecimento e, quando muito, destinando a ela o quase ou meta-conhecimento, a aptidão geral das faculdades do conhecimento envolvidas (imaginação, entendimento) para indicarem um conhecimento possível. ${ }^{22}$ Em Kant, o meio de um tal auto-asseguramento da subjetividade teórica não é o auto-conhecimento e tampouco é o conhecimento dos objetos envolvidos, mas sim o sentimento puramente subjetivo ou, mais precisamente, o sentimento de prazer e desprazer na forma estética no caso do belo e na ausência estética de forma [ästhetischer Formlosigkeit] no caso do sublime.

Schopenhauer transforma a disponibilidade para o conhecimento do estado subjetivo (sentimento), que Kant tornou válida junto ao sujeito esteticamente afinado, em algo objetivo [ObjektivGegenständliche], fazendo dela um conhecimento sui generis, a saber, um conhecimento ideal das formas puras de tudo o que

22. Cf. Kant, I. Crítica da faculdade do juízo. In: Kant's Gesammelte Schriften, bd. 5, p. 217. 
pode ser conhecido particularmente. Com isso, numa perspectiva kantiana, as Ideias de Schopenhauer mostram-se não tanto como super-objetos supra-sensíveis para super-homens artísticos, mas como os princípios intuitivamente dados do conhecimento objetivo. Para Schopenhauer, a arte consegue num instante e em cada uma de suas obras (bem-sucedidas), aquilo que a filosofia pode apenas aspirar e alcançar somente de maneira aproximada: o conhecimento dos princípios do mundo como representação. De resto, o próprio Kant - com o conceito de Ideias estéticas como intuições que escapam por princípio à articulação conceitual ("intuições inexponíveis" $)^{23}$ - forneceu a Schopenhauer um modelo para a capacidade de a arte expor coisas que não podem ser transmitidas discursivamente.

Se tomarmos o conhecimento estético das Ideias em Schopenhauer, que parte da crítica do conhecimento de Kant e recorre à sua crítica do juízo estético, como quase-conhecimento apresentado artisticamente acerca do mundo pré-individuado como representação, então aguça-se também a visão da distância que separa a Metafísica da Arte de Schopenhauer da Doutrina das Ideias de Platão. Para Platão, as Idéias, além de sua função enquanto princípios da determinidade dos objetos sensíveis, possuem o estatuto de formas mesmas, presentes intuitivamente em objetividade determinada ou, mais precisamente, de formas que se apresentam e são objeto do saber e que, a rigor, constituem

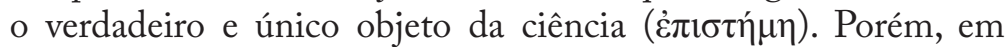
Schopenhauer falta às Ideias apresentadas esteticamente na arte a própria determinidade objetiva, assim como a exponibilidade científica.

Sob um outro ponto de vista, especificamente de filosofia da arte, manifesta-se também uma distinção que não é insignificante entre a Doutrina Estética das Ideias em Schopenhauer e a Ciência das Ideias de Platão. Para Platão, toda arte, enquanto representa-

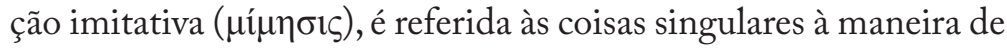
uma cópia, e não, por exemplo, às Ideias. Disso resulta a inferiori-

23. Cf. Idem, p. 314. 
dade ontológica de toda arte imitativa em Platão, pois estas artes, ao invés de se voltarem às Ideias, com um propósito filosófico, fazem apenas a imitação inferior das essências supra-sensíveis e espirituais por meio do mundo sensível e fazem dos entes sensíveis, por sua vez, novamente um objeto, no melhor dos casos, de segunda categoria. Com o direcionamento constitutivo da arte para as Ideias, Schopenhauer se esquiva da crítica platônica à arte e supervaloriza o acesso, mediado discursivamente, da ciência ao mundo como representação, por meio do acesso intuitivo e direto da arte a ele. Numa inversão completa das relações platônicas, em Schopenhauer as ciências são referidas e limitadas às relações espaço-temporais de dependência às coisas individuais, ao passo que justamente a arte, por detrás das coisas, é capaz de penetrar na essência do mundo como representação.

Em Schopenhauer, somente a filosofia pode apreender a essência, por meio da arte, com sua perspectiva que supera toda a individualidade - em suas formas fundamentais, enquanto temporalidade, espacialidade e racionalidade. Tal como a arte, a filosofia está relacionada no todo ao mundo e tem como meta a exposição do mundo como tal. Todavia, a filosofia e a arte diferenciam-se quanto ao meio e a modalidade da exposição do mundo, que é comunicado discursivamente na filosofia e que se dá em uma aproximação infinita, enquanto a arte, com seu acesso intuitivo à estrutura ideal do mundo, "em toda parte está em ação". ${ }^{24}$ A relação imitativo-mimética, assim como revelatório-apofântica com o mundo, que a arte e a filosofia têm fundamentalmente em comum, é compreendida por Schopenhauer preferencialmente como "repetição" 25: filosofia e arte oferecem ambas uma repetição do mundo, uma a oferece no conceito, a outra na imagem.

Mediante a determinação essencial comum à arte e à filosofia, enquanto repetição do mundo, Schopenhauer operou mais uma mudança que se distancia da avaliação platônica da arte. Ao

24. Schopenhauer, A. Die Welt als Wille und Vorstellung. Erster Band. In: Sämtliche Werke, p. 218.

25. Cf. Idem, p. 312. 
invés de opor o conhecimento filosófico e não-artístico das Ideias à cópia artística e não-filosófica das coisas individuais, tal como Platão, Schopenhauer transpõe à filosofia a compreensão fundamental da arte como imitação. Assim, a filosofia se mostra como a arte do conceito na imitação do mundo. Schopenhauer mesmo acentua o caráter artístico da filosofia, em sua ligação específica de intuitividade e artificialidade, quando ele compreende e representa a própria filosofia como o desdobramento discursivo e artificial de uma única e imediata perspectiva fundamental, mas que se deixa comunicar não como tal, mas somente de maneira indireta, acima de sua mediação discursiva. ${ }^{26} \mathrm{Com}$ a assimilação tendencial da filosofia à arte se associa também a avaliação fundamental de Schopenhauer do modo de validade de seu sistema filosófico, que não deve consistir em provas logicamente conclusivas e em evidências não controversas, mas que repousa na plausibilidade cumulativa e quase experimental de uma dupla hipótese metafísi$\mathrm{ca}$ - a do mundo como vontade e como representação - a qual, por sua vez, possui o caráter de uma analogia bem fundamentada, mas não propriamente demonstrada (e também de modo algum demonstrável), por meio da qual algo de antropomórfico, nossa natureza volitiva, é extrapolada na direção cósmica ("Mundo como "Macrantropos"). ${ }^{27}$

\section{V.A unicidade de música e mundo}

A afinidade entre arte e filosofia, estabelecida por Schopenhauer, parece esbarrar em seus limites na passagem sistemática da filosofia entre a consideração do mundo como representação e a sua consideração como vontade. $\mathrm{Na}$ verdade, a arte deve poder trazer também à exposição intuitiva, no âmbito das Ideias, o caráter da vontade movido pela vontade, e que traz consigo o prazer e o sofrimento. Schopenhauer acentua especialmente a capa-

26. A esse respeito, Cf. Malter, R. Der eine Gedanke. Hinführung zur Philosophie Arthur Schopenhauers. Darmstadt: Wissenschaftliche Buchgesellschaft, 1988.

27. Schopenhauer, A. Die Welt als Wille und Vorstellung. Zweiter Band. In Sämtliche Werke, p. 739. 
cidade da arte trágica ("Tragédia") para a exposição do sofrimento assim como para a exposição da resignação resultante do sofrimento. ${ }^{28}$ Por este motivo, a tragédia antiga e moderna tornam-se, para Schopenhauer, uma propedêutica estética da ética da negação da vontade. Entretanto, para a arte em seu todo, incluindo a tragédia, é constitutivo um elemento de distância estética, sem o qual arte e vida coincidiriam indistintamente, e através do qual, porém, arte e vida permanecem sempre separadas.

Contudo, a separação fundamental com relação à vida, apesar de toda a relação imitativo-reveladora, vale não só para a arte, mas também para a filosofia. A teoria transcendental do mundo como vontade e como representação é completamente relacionada ao mundo no modo da cópia. A repetição do mundo no conceito abarca então também a ética no Quarto Livro do Mundo como Vontade e Representação, no qual a afirmação da vontade e a negação da vontade são apresentadas teoricamente, sem que com isto estivesse associada a pretensão a um efeito ético direto no leitor. Muito pelo contrário, Schopenhauer acentua a impossibilidade de promover a moralidade através da teoria moral. ${ }^{29}$ Somente a libertação do intelecto com relação à vontade, que deve ser alcançada de maneira autônoma por cada um, na filosofia vivida do ethos ascético, suprime a distância que o conhecimento filosófico mantém em relação à vida. Porém, a práxis da vida ascética tem como meta justamente a negação da vontade de vida e, com isto, a negação da própria vida. Com a distância em relação à vida, a ética filosófica tornada ética suprime tendencialmente a própria vida.

Schopenhauer acredita, porém, ainda poder reivindicar para a arte a vontade que se retrai duplamente, que permanece distanciada teoricamente na exposição estética, ao passo que é negada de maneira prática na vida ética, na medida em que distingue, com ênfase e empatia, a essência metafísica e o efeito estético de uma forma artística - a música - diante da eficácia das outras artes.

28. Cf. Schopenhauer, A. Die Welt als Wille und Vorstellung. Erster Band. In: . Sämtliche Werke, p. 298-301.

29. Cf. Idem, p. 319 e ss. 
Para Schopenhauer, a diferença entre a música e as outras artes não é meramente exterior, que pudesse se esgotar na diferença do meio e do material. Pelo contrário, a criação e a consumação da música devem ser de natureza inteiramente diferentes do que a produção e a recepção estética nas outras artes.

Entretanto, apesar de toda a diferença específica da música frente às outras artes, defendida por Schopenhauer, ele acentua também a identidade genérica de todas as artes, inclusive da música, em sua "relação de cópia" com a realidade. ${ }^{30}$ Com isto, coloca-se para a filosofia da música de Schopenhauer a dupla tarefa de distinguir especificamente a música em relação a todas as outras artes, sem descuidar do caráter fundamentalmente imitativo destas. A solução que desenvolve do problema estético da música é, por sua vez, exposta por Schopenhauer tal como toda a sua filosofia e suas partes principais, não de maneira apodítica e com pretensão a uma certeza completa, mas no modo deliberativo de uma intelecção originária, que lhe foi concedida, e que se distingue por meio de sua eficácia explicativa diante de outras eventuais explicações do modo de ser e de fazer efeito da música. ${ }^{31}$

A especificidade da música enquanto arte, segundo Schopenhauer, pode ser vista no fato de que a relação de cópia da música não diz respeito ao mundo enquanto tal, mas à própria vontade que está na base do mundo e que nele aparece. Digno de nota nessa identificação do objeto específico da mímese musical é que a distinção da música com relação às outras artes não se realiza por meio do recurso à distinção central entre mundo como representação e mundo como vontade. Com isto Schopenhauer leva em conta a circunstância de que talvez não apenas o mundo como representação, mas também, de modo pleno, o mundo como vontade pode ser objeto da exposição imitativa por meio das outras artes - principalmente quando, a saber, a imitação artística no âmbito das Ideias se refere à conflituosidade, determinada pela

30. Cf. Idem, p. 303.

31. Cf. Idem, p. 303 e ss. 
vontade, do acontecimento do mundo, tal como ocorre, de maneira paradigmática, na tragédia.

Do ponto de vista formal, é na ausência da relação imitativa às Ideias que Schopenhauer fixa a diferença específica da música com relação às outras artes. ${ }^{32}$ Todas as outras artes relacionam-se imitativamente às Idéias, como princípios que estruturam objetivamente o mundo. Com isso, elas se referem indiretamente ao mundo, por meio das Ideias. Somente a música contorna as Ideias e, com isto, também o mundo estruturado pelas mesmas, para adentrar numa relação de cópia com algo inteiramente diferente do mundo e de suas Ideias, a saber: com a própria vontade. É certo que também a vontade está relacionada com o mundo, ao aparecer nele - assim como, inversamente, também o mundo está relacionado à vontade, a saber, como seu fenômeno. Porém, em Schopenhauer, a própria vontade e enquanto tal é independente do mundo. A vontade nem nasce no mundo como seu fenômeno, nem o mundo é idêntico à vontade como sua essência secreta.

Naturalmente, Schopenhauer não tem dúvidas de que a música não simplesmente ou não propriamente consegue copiar algo de tal maneira inobjetual e indisponível como a própria vontade enquanto tal. Por isso, Schopenhauer modifica a descrição genérica da arte como imitação, ao não fazer valer nenhuma imitação intencional para o caso particular da música e sua relação representativa com a vontade; antes, faz valer uma relação de manifestação - a manifestação da vontade na música e enquanto música. Todavia, então há também uma relação de "analogia" ou de "paralelismo" 33 entre a relação de manifestação musical, em pequena escala, da vontade na música e enquanto música e a relação de manifestação cósmica, em grande escala, da vontade no mundo e enquanto mundo. Em ambos os casos a vontade aparece fora de si e, contudo, como ela mesma - por assim dizer, em imagem, na imagem reduzida da música e na imagem ampliada do mundo.

32. Cf. Idem, p. 304.

33. Idem, ibidem. 
Assim, resulta uma dupla referência da música enquanto arte. A música tem seu "objeto" [Objekt] ou seu assunto [Gegenstand] na vontade que nela se manifesta, de modo que ela pode ser considerada como sua "cópia" $[$ Abbild $]$ imediata. ${ }^{34}$ Porém, além dessa referência direta à vontade, ela possui também uma referência indireta e mediada ao mundo, na medida em que a música, assim como o mundo, é um fenômeno ou manifestação da vontade. A vontade funciona então como o "ponto de comparação" da música e do mundo, os quais devem ser considerados como modos de manifestação da vontade que atuam paralelamente e, por isto, estão em analogia entre si. ${ }^{35} \mathrm{~A}$ posição metafísica da música em Schopenhauer, que pode ser qualificada como exorbitante, consiste portanto em sua originalidade simultânea [Gleichursprünglichkeit] com o mundo. Se, para Schopenhauer, toda arte representa já a "atividade propriamente metafísica" ${ }^{36}$ do homem, então a música, enquanto arte excepcional, é ao mesmo tempo a arte par excellence ou a arte propriamente metafísica. Pois, diferentemente das demais artes, ela não está situada imitativamente depois do mundo no âmbito mimético das Ideias, mas é igualada a ele enquanto fenômeno igualmente originário da vontade, enquanto música-mundo e mundo-música, tal como se poderia denominá-los à luz da concepção e exposição de Schopenhauer. Aliás, Schopenhauer chega não apenas a agregar e classificar a música ao mundo, mas até mesmo a sobrepô-la e antepô-la ao mundo, na medida em que a música expõe a cópia imediata da vontade e, com isto, está ainda mais próxima da vontade do que o mundo, com suas múltiplas ob-

34. Cf. Idem, pp. 312 e 310.

35. Cf. Idem, pp. 303 e ss.

36. Esta é a formulação nietzschiana, desenvolvida a partir de Schopenhauer, para a capacidade da arte para a justificação teórica e prática da vida, que em Nietzsche, todavia, implica a total substituição da moral pela arte. Cf Nietzsche, F. O Nascimento da Tragédia. Prefácio a Richard Wagner e Ensaio de uma autocrítica. In: Kritische Studienausgabe, vol. 1, pp. 24 e 17. A respeito da relação entre Nietzsche e Schopenhauer, ver Zöller, G. “Schopenhauer”. In: Birx, H. J.; Knoepffler, N.; Sorgner, S. L. (Hrsg). Wagner und Nietzsche. Kultur - Werk - Wirkung. Ein Handbuch. Rororo enzyklopädie. Reinbeck: Rowohltz, 2008, p. 355-72. 
jetivações da vontade: "Portanto, poder-se-ia denominar o mundo tanto música corporificada quanto vontade corporificada". ${ }^{37}$

\section{A unicidade de vontade e representação}

Schopenhauer desenvolve sua decidida interpretação metafísica da música como manifestação da vontade paralela ao mundo a partir da perspectiva geral da experiência estética e em especial lançando mão, em termos fenomenológicos, do modo de agir particular da música. Considerando o efeito estético da música, Schopenhauer constata "que ela [isto é, a música] age imediatamente sobre a vontade". ${ }^{38} \mathrm{Na}$ comoção afetiva universal provocada pela música - em seu profundo efeito sobre a vontade humana - Schopenhauer vê um sinal de sua particular e exclusiva proximidade com a própria vontade e como tal. $\mathrm{Na}$ música, segundo a avaliação de Schopenhauer, é atuante a vontade tornada imediatamente manifesta na música e como música, e isso sobre a vontade do sujeito da experiência musical, sem a interposição de conhecimentos mediadores e, sobretudo, sem a mediação das Ideias.

Não obstante sua imediatidade constitutiva, o efeito estético da música não é indeterminado e indiferenciado. Pelo contrário, segundo Schopenhauer, justamente o modo de atuação específico da música é constituído pelo fato de que nela faz efeito uma vontade claramente diferenciada. À múltipla configuração da própria vontade como vontade humana em modificações plurais e múltiplas, e até mesmo infinitas da vontade ou dos sentimentos - como alegria ou tristeza - corresponde um efeito análogo naquele que, afinado pela vontade, recebe a música, e em quem ela induz tais estados de sentimentos diferenciados. Devido ao seu papel como mediadora de múltiplas configurações de sentimentos de todo tipo e à sua capacidade de fazê-lo de maneira imediata e universal, Schopenhauer compara a música com uma linguagem universal desprovida de conceitos, que pode ser compreendida sem que ela

37. Schopenhauer, A. Metaphysik des Schönen, p. 222.

38. Schopenhauer, A. Die Welt als Wille und Vorstellung. Zweiter Band. In Sämtliche Werke, p. 512. 
possa ser traduzida de maneira adequada para um outro modo de expressão. ${ }^{39}$

Sem dúvida - segundo a avaliação de Schopenhauer - a determinidade afetiva da música e a experiência afetiva provocada por ela não são inteiramente idênticas às manifestações análogas da Vontade provocadas de maneira extra-musical. As determinações musicais da vontade são certamente determinadas de um ponto de vista formal, mas são indeterminadas ou vazias quanto ao conteúdo. Em particular, falta às (quase) emoções musicais a determinidade objetiva ou objetividade [Objektivität] intencional dos sentimentos. Se a música provoca alegria ou tristeza e por causa desse efeito é considerada, com boa razão, como a sua expressão, então a alegria ou a tristeza não são esta alegria ou tristeza determinadas, dizendo respeito a uma circunstância determinada, mas sim, são o sentimento genérico da tristeza ou da alegria. Por isso, para Schopenhauer, os sentimentos musicais reduzem-se à estrutura de sentimentos, de modo que a música, no que concerne à sua dimensão sentimental, deve ser considerada como "mera forma sem matéria [Stoff]" e como "mundo dos espíritos, sem matéria [Materie]" ${ }^{40}$

Entretanto, a diferença das determinações musicais da vontade com relação às modificações extramusicais da vontade não se limita à distinção entre sentimentos plenos e sentimentos da forma. As formas musicais do sentimento, enquanto formas do sentir separadas dos sentimentos reais, também não são mais aquilo que, tal como os sentimentos reais, podem efetivamente ser sentidas. Pelo contrário, os quase-sentimentos musicais são reconhecidos, eles são objeto da representação e, nesse sentido, devem ser enquadrados no mundo como representação. Com isto, confirma-se, uma vez mais, a analogia da música com as outras artes, na qual Schopenhauer insiste, apesar da dissociação da música com relação ao conhecimento das Ideias:

39. Cf. Schopenhauer, A. Metaphysik des Schönen, p. 22 e ss; cf. também Schopenhauer, A. Die Welt als Wille und Vorstellung. Erster Band. In:

Sämtliche Werke, p. 309.

40. Cf. Schopenhauer, A. Die Welt als Wille und Vorstellung. Zweiter Band. In . Sämtliche Werke, p. 514. 
Vemos aqui, portanto, os movimentos da vontade serem lançados ao âmbito da mera representação, o qual é o palco exclusivo da eficácia de todas as belas-artes; pois estas exigem inteiramente que a vontade mesma permaneça fora de jogo e nós nos comportemos inteiramente como [seres] puramente conbecedores. ${ }^{41}$

Somente a equiparação estética da música às outras artes e a incorporação, associada a isso, da diferença estética entre o mundo copiado artisticamente e a imagem que reproduz o mundo impedem que as modificações musicais da vontade afetem imediatamente a vontade e, assim, atuem de maneira extra-estética - como sentimentos reais. Por isso, a música como arte não tem a ver com sentimentos sentidos, mas somente com sentimentos representados ou reconhecidos. ${ }^{42} \mathrm{~A}$ música artística oferece sempre apenas sentimentos fingidos e também conduz sempre apenas a uma emocionalidade fictícia.

Segundo a avaliação de Schopenhauer, nesse caso a ficcionalidade emocional da música substitui os sentimentos reais por sentimentos artificiais copiados artisticamente:

Por conseguinte, as afecções mesmas da vontade, ou seja, a dor real e o estado de ânimo real, não devem ser suscitadas, mas apenas seus substitutos que, adequados ao intelecto, como imagem da satisfação da Vontade e como o que em maior ou menor grau se lhe opõe como imagem da maior ou menor dor. ${ }^{43}$

Assim, em Schopenhauer, a música é certamente a cópia da vontade como tal e, neste sentido, a arte propriamente metafísica, mas nesse caso sempre apenas a cópia da vontade e, neste sentido

41. Idem, p. 516 .

42. Sobre a diferença sistemática e histórica entre a música como arte e a música como poder, cf. Zöller, G. "Musikalische Macht. Musikphilosophie als politische Philosophie”. In: Tadday, U. (Hrsg). Musik-Konzepte. Neue Folge. XI/2007. Sonderband Musikphilosophie. München: 2007, p. 152-66.

43. Schopenhauer, A. Die Welt als Wille und Vorstellung. Zweiter Band. In Sämtliche Werke, p. 516. 
- como toda arte - distinta e separada da vida e de sua alternância sem fim de prazer e sofrimento.

A redução estética dos sentimentos aos seus substitutos cognitivos na figura de formas genéricas do sentimento concede um foco formal à música em Schopenhauer, que contrabalanceia inteiramente o direcionamento declarado da música, em termos de conteúdo, na direção da vontade. À compreensão complementar e equilibrada da música como forma pertence também o caráter de repetição afirmado por Schopenhauer, e que é constitutivo da música. Para Schopenhauer, a música como tal repete não apenas o mundo como tal num espelhamento estético, mas também, no interior dela mesma, ela é marcada profundamente pelo princípio formal da repetição. O próprio Schopenhauer nos recorda da forma Da Capo nas árias e em outras estruturas composicionais da música. ${ }^{44}$ Mas também sob um aspecto mais amplo e mais essencial a música deveria ser considerada, na perspectiva schopenhaueriana, como a arte da repetição par excellence: quanto ao decurso formal do retorno do início, ao final [da peça]; quanto à prática de múltiplas execuções da mesma obra; quanto à totalidade do repertório da atividade musical, sobretudo, porém, quanto ao caráter fundamental da música, a saber, de produzir um mundo de sonoridades altamente diferenciado, com o mínimo de elementos - classicamente, com uma dúzia de sons distintos e dois modos musicais ou, excepcionalmente, com apenas "doze sons relacionados entre si" (A. Schönberg) - e isto, de maneira sempre diversa, porém jamais sem o recurso ao mesmo material. Também nisto a música se assemelha ao mundo real, no qual [as coisas] podem acontecer de maneira muito colorida, mas, na verdade, o mundo é pintado com pouquíssimas cores e formas.

Assim, em sua fundamentação da expressão musical dos sentimentos e de como estes podem ser suscitados com meios musicais, a filosofia da música de Schopenhauer mostra-se, de modo peculiar, distanciada da emocionalidade e orientada essencialmen-

44. Cf. Schopenhauer, A. Die Welt als Wille und Vorstellung. Erster Band. In: . Sämtliche Werke, p. 312. 
te para decursos formais e especialmente à repetição modificada ou à "variação em desenvolvimento" (A. Schönberg) como princípio artístico da música. Delineia-se, assim, uma afinidade ou compatibilidade entre a Metafísica da Música de Schopenhauer e a posição estética que aparentemente é inteiramente oposta a ela e que, juntamente com a interpretação schopenhaueriana do som [Ton], marcou o pensamento sobre música e em música no decurso seguinte do século XIX, adentrando até o século XX, a saber, o formalismo radical de Eduard Hanslick, em seu ensaio decisivo intitulado Do Belo Musical (1854), segundo o qual o conteúdo estético específico da música são "formas sonoras em movimento". ${ }^{45}$ Exatamente do mesmo modo que a determinação formalista de Hanslick da música como arte permite a consideração complementar do "conteúdo espiritual" da música, e até mesmo o antecipa, ${ }^{46}$ a determinação de Schopenhauer da metafísica da música possibilita e exige o complemento através da concepção artística da música como forma. Assim, ao duplo caráter metafísico da música como vontade e representação corresponde seu duplo caráter estético como sentimento e forma.

Tradução de Mário Videira

\section{Bibliografia}

ADORNO, T. W. Beethoven. Philosophie der Musik. Fragmente und Texte. Hrsg. von Rolf Tiedemann. Frankfurt/M.: Suhrkamp Verlag, 1993.

D‘ALFONSO M. V. Schopenhauers Kollegnachschriften der Metaphysikund Psychologievorlesungen von G. E. Schulze (Göttingen, 1810-11). Würzburg: Königshausen \& Neumann, 2008.

45. Hanslick, E. Vom Musikalisch-Schönen. Ein Beitrag zur Ästhetik der Tonkunst. Leipzig 1854. Nachdruck Darmstadt: Wissenschaftliche Buchgesellschaft, 1976, p. 32 (grifos no original).

46. Idem, p. 103 ("reivindicação do conteúdo espiritual”). Sobre a afinidade secreta entre Schopenhauer e Hanslick, cf. Zöller, G. "Schopenhauer". In: Birx, H. J.; Knoepffler, N.; Sorgner, S. L. (Hrsg). Wagner und Nietzsche. KulturWerk - Wirkung. Ein Handbuch, p. 109 e ss. 
FICHTE, J. G.. J. G. Fichte-Gesamtausgabe der Bayerischen Akademie der Wissenschaften. Hrsg. von Reinhard Lauth u.a.. Stuttgart-Bad Cannstatt: Frommann-Holzboog, 1962ss.

.Züricher Vorlesungen über den Begriff der Wissenschaftslehre. Februar 1794. Nachschrift Lavater. Hrsg. von Erich Fuchs. Neuried: Ars una, 1996.

HANSLICK, E. Vom Musikalisch-Schönen. Ein Beitrag zur Ästhetik der Tonkunst. Leipzig 1854. Nachdruck Darmstadt: Wissenschaftliche Buchgesellschaft, 1976.

KANT, I. Kant's Gesammelte Schriften. Hrsg. von der Preußischen Akademie der Wissenschaften (vol.1-22), der Deutschen Akademie der Wissenschaften zu Berlin (vol. 23) und der Akademie der Wissenschaften zu Göttingen (a partir do vol. 24). Berlin: Walter de Gruyter, 1900ss.

MALTER, R. Der eine Gedanke. Hinfübrung zur Philosophie Arthur Schopenhauers. Darmstadt: Wissenschaftliche Buchgesellschaft, 1988.

Arthur Schopenhauer. Transzendentalphilosophie und Metaphysik des Willens. Stuttgart-Bad Cannstatt: Frommann-Holzboog, 1991.

NIETZSCHE, F. Kritische Studienausgabe. Hrsg. von Giorgio Colli und Mazzino Montinari. Berlin, New York: Walter de Gruyter \& Co. 1999.

PLATÃO. Fédon. Trad. de F. D. E. Schleiermacher. In: . Werke in acht Bänden. Griechisch und deutsch. Hrsg. von Günther Eigler, vol. 3. Darmstadt: Wissenschaftliche Buchgesellschaft, 1974.

SCHOPENHAUER, A. Die Welt als Wille und Vorstellung. Erster Band. In: ___. Sämtliche Werke. Hrsg. von Arthur Hübscher. Dritte Auflage. Wiesbaden: Brockhaus, 1972.

. Die Welt als Wille und Vorstellung, Zweiter Band. In:

Sämtliche Werke. Hrsg. von Arthur Hübscher. Dritte Auflage. Wiesbaden: Brockhaus, 1972.

. Der handschriftliche Nachlaß. Hrsg. von Arthur Hübscher, vol. 1. Frühe Manuskripte (1804-1818), München: Deutscher Taschenbuch Verlag, 1985.

. Metaphysik des Schönen. Hrsg. von Volker Spierling. München, Zürich: Piper, 1985.

WAGNER, R. "Beethoven". In: Dichtungen und Schriften. Jubiläumsausgabe in zehn Bänden. Hrsg. von Dieter Borchmeyer. vol. 9. Frankfurt/M: Insel, 1983. 
ZÖLLER, G. "Schopenhauer und das Problem der Metaphysik. Kritische Überlegungen zu Rudolf Malters Deutung". In: Schopenhauer-Jabrbuch 77, 1996, p. 51-63. . "German Realism. The Self-Limitation of Idealist Thinking in Fichte, Schelling and Schopenhauer".In: AMERIKS, K. (Hrsg.). The Cambridge Comnpanion to German Idealism. Cambridge: Cambridge University Press, 2000.

. "Arthur Schopenhauer". In: FÜRBETH, O.; SORGNER, S. (Hrsg.) Musik in der deutschen Philosophie. Eine Einführung. Stuttgart, Weimar: Metzler, 2003.

. "Die Möglichkeiten und Grenzen der Vernunft. Kant und der deutsche Idealismus“. In: FISCHER, E.; VOSSENKUHL. W. (Hrsg.) Die Fragen der Philosophie. Einfübrung in die Disziplinen und Epochen der Philosophie. München: C.H. Beck, 2003.

. "Kichtenhauer. Der Ursprung von Schopenhauers Welt als Wille und Vorstellung in Fichtes Wissenschaftslehre 1812 und System der Sittenlehre". In: HÜHN, L. (Hrsg.) Die Ethik Arthur Schopenhauers im Ausgang von Deutschen Idealismus (Fichte/Schelling). In redaktioneller Zusammenarbeit mit Philipp Schwab. Würzburg: Ergon Verlag, 2006.

"Musikalische Macht. Musikphilosophie als politische Philosophie". In: TADDAY, U. (Hrsg). Musik-Konzepte. Neue Folge. XI/2007. Sonderband Musikphilosophie. München: 2007. "Schopenhauer". In: BIRX, H. J.; KNOEPFFLER, N.; SORGNER, S. L. (Hrsg). Wagner und Nietzsche. Kultur - Werk Wirkung. Ein Handbuch. Rororo enzyklopädie. Reinbeck: Rowohltz, 2008. 